\title{
Carotid-cavernous fistula
}

\section{Fístula carotídeo-cavernosa}

Manuel Augusto Pereira Vilela'

\begin{abstract}
Carotid cavernous fistulae are an uncommon disease. They are classified as direct or indirect. In direct fistulas there is an abnormal communication between the internal carotid artery and the cavernous sinus. Indirect forms have an abnormal bypass between the meningeal branches of the internal and/or external carotid arteries and the same sinus. The purpose of this article is to provide an overview of the anatomy of the envolved area and the clinical findings, diagnostic evaluation and treatment.

Keywords: Carotid-cavernous sinus fistula; Carotid artery; Cavernous sinus
\end{abstract}

\section{RESUMO}

Fístulas carotídeo-cavernosas são raras. São classificadas nos tipos direto e indireto. Fístulas diretas têm uma comunicação anormal entre a artéria carótida interna e o seio cavernoso. Nas formas indiretas a conexão se faz entre os ramos meningeos da carótida interna e/ou externa e o mesmo seio. O propósito deste artigo é o de atualizar os conceitos anatômicos, clínicos, diagnósticos e terapêuticos desta situação.

Descritores: Fístula carotídeo-cavernosa; Artéria carótida interna; Seio cavernoso

1 Ophthalmology Department, Pelotas Federal University (UFPel) Medical School — Pelotas (RS), Brazil.

*Study conducted at the Pelotas Federal University (UFPel) — Pelotas (RS), Brazil.

The authors declare no conflicts of interest

Received for publication: 22/12/2011 - Accepted for publication: 13/2/2012

Rev Bras Oftalmol. 2013; 72 (1): 70-5 


\section{INTRODUCTION}

A nomalous communication between the internal carotid artery (ICA) or its branches and/or branches of the external carotid artery (ECA) with the cavernous sinus causes an abrupt change in the direction and distribution of brain and orbital blood flow — an uncommon condition of varying severity.

The condition typically presents with pulsating proptosis with murmur, and most cases can mimic conjunctivitis, unilateral glaucoma or Graves' disease ${ }^{(1,2)}$.

The anatomical complexity of the region can be assessed by increasingly sophisticated, high-resolution neuroimaging techniques that significantly improve the accuracy of topographic diagnosis and therapeutic access ${ }^{(3-6)}$.

The aim of this review is to update the anatomical, clinical, and therapeutic knowledge related to carotid-cavernous fistula (CCF).

\section{Anatomy of the carvenous}

The cavernous sinuses (CSs), like all other cerebral sinuses, are venous channels (or extra-dural plexuses) formed by the inner and outer layers of the dura mater (DM). Also called the pachymeninx, the DM consists of a thick, resistant tissue rich in collagen fibres, blood vessels and nerves ${ }^{(7)}$.

The CS occupies a small territory in the middle cranial fossa (parasellar location, lateral to the sphenoid sinus). It is $2-\mathrm{cm}$ long and $1-\mathrm{cm}$ wide, extending from the orbit to the petrous apex. Its osseous boundaries include the body and wings (greater and lesser) of the sphenoid, the tuberculum and dorsal part of the sella, the carotid groove, and the clinoid processes ${ }^{(4,8)}$.

The DM covers the superior, lateral (with the sheaths of nerves III, IV, V1 [first branch of V], and possibly V2) and medial (fused with the periosteum of the sella) surfaces; the middle cranial fossa forms the lower surface ${ }^{(7,8)}$.

The CS is a venous plexus that receives the blood returning from the eyes and orbits through the superior orbital fissure, individually or in a common trunk, via the superior orbital vein (SOV) and the inferior orbital vein (IOV, which is connected with the facial vein and may flow to the pterygoid plexus through the inferior orbital fissure), as well as the superficial middle cerebral vein, the inferior cerebral vein (including the uncal vein, temporal lobe), the sphenoparietal (vein or sinus, receiving the flow from the middle cerebral vein and variable contributions from the inferior frontal, anteromedial temporal, orbital, and meningeal veins), and pituitary veins. The SOV is formed by the junction of the angular and frontal veins in the anterior orbit, with a diameter of approximately 2 to $3.5 \mathrm{~mm}$, which can change with head position or the Vasalva manoeuvre ${ }^{(3,4,9,10)}$.

CS drainage flows to the superior petrosal sinus (SPS, which empties into the junction of the sigmoid and transverse sinuses) and the inferior petrosal sinus (IPS, with empties into the jugular bulb), communicating with the contralateral CS at the clivus (intercavernous plexus or circular sinus) ${ }^{(8)}$. The basilar venous plexus connects the CS to the epidural vertebral plexus; multiple emissary veins interconnect the CS inferiorly to the pterygoid plexus through the foramen ovale ${ }^{(3,4,7,9)}$.

Cranial nerves III, IV, VI, and V1 run along the CS, as well as sympathetic and parasympathetic fibres and the $\mathrm{ICA}^{(11)}$. The ICA is subdivided into seven segments: cervical (C1), petrous (C2), lacerum (C3), cavernous (C4), clinoid (C5), ophthalmic (C6), and communicating (C7). The branches emerging at the CS comprise: (a) the meningo-hypophyseal trunk (the origin of the inferior hypophyseal, the marginal and basal tentorial [the Bernasconi-Cassinari branch, which anastomoses with the ophthalmic], and lateral clival and dorsal meningeal branches), (b) the posterior and inferior hypophyseal arteries, (c) the inferolateral trunk (or inferior artery of the CS, which subdivides into the superior, anteromedial, anterolateral [which anastomoses with branches of the internal maxillary]), and posterior branches, (d) McConell's capsular artery, and, less frequently, (e) the ophthalmic artery. The ECA reaches the CS through the accessory meningeal artery (a branch of the middle meningeal or maxillary artery) which connects to the branches of the inferolateral trunk and the ascending branch of the pharyngeal ${ }^{(7,12,13)}$

The cranial nerves (except VI) are situated along the lateral wall of the sinus, in the following order from top to bottom: III, IV (which appears in the orbit outside the annulus of Zinn) and V1. The abducens nerve runs medially to the ophthalmic and laterally to the ICA. The sympathetic fibres run along the surface of the ICA, join the VI nerve and are distributed with V1, with which they reach — through the long ciliary nerves — the pupil dilator muscle. Some sympathetic fibres run directly from the carotid plexus to the ciliary ganglion; others travel directly with the ophthalmic artery to the eyeball ${ }^{(4,9,12,14,15)}$.

\section{Manifestations}

Given its variable severity, CCF has been classified according to different parameters with the ultimate goal of indicating the best therapeutic approach. Thus it is common to find descriptions based on aetiology (spontaneous or traumatic) or flow conditions (high or low) ${ }^{(16-18)}$. However, these classifications are incomplete, as they do not relate to prognosis or management. The most used classification has been proposed by Barrow et al. ${ }^{(12)}$ and is based on the arterial supply of these communications (Table 1).

CCF type $\mathrm{A}$ is the only type with direct communication between the ICA and the CS, therefore high flow is usually present (in $5 \%$ of cases, the entire flow moves through this connection). A compilation of different series shows that brain

Table 1

Classification of $\mathrm{CCF}^{(12)}$

\begin{tabular}{cl}
\hline Type & Features \\
\hline A & Direct communication between the ICA and the CS (high flow, more common after trauma) \\
B & Communication between branches of the ICA and the CS (rare) \\
C & Communication between branches of the ECA and the CS \\
D & Communication between branches of both the ICA and ECA and the SC (low flow; most frequent) \\
\hline
\end{tabular}


trauma (including iatrogenic trauma) is responsible for up to $80 \%$ of cases, the others occurring spontaneously (aneurysm rupture or weakness of the vascular wall in cases of collagen deficiency, such as Ehlers-Danlos syndrome ${ }^{(19)}$, fibromuscular dysplasia, pseudoxanthoma elasticum, osteogenesis imperfecta, or atherosclerosis) ${ }^{(20)}$. While acute forms occur more often in young men, spontaneous forms tend to occur in middle-aged women $^{(3,8,9,12,21-23)}$.

There is much disagreement regarding how direct trauma (especially blunt trauma) causes damage to the ICA wall, and particularly on bone fracture as a precondition ${ }^{(24)}$. Gobin et al. ${ }^{(25)}$ detected trauma in $95 \%$ of cases. In 42 cases of CCF type A presented by Helmke et al. ${ }^{(9)}$ there was no evidence of trauma. The authors then suggested that the distension of the vascular wall caused by a sudden increase in intraluminal pressure can explain many of these cases. In fact, several features of this vascular segment make it prone to shunting, among them the amount and direction of ligaments in relation to the adventitia, the conformation and mobility of the siphon (horizontal segment), the inextensibility of the dura, and adjacent bones ${ }^{(8,14,26)}$. Iatrogenic causes in CCF type A include perforation by catheters or balloons during endovascular procedures, post-septoplasty, transsphenoidal surgery, LeFort type 1 maxillary osteotomy, and access to the Gasserian ganglion in trigeminal diseases ${ }^{(22,25,2728)}$.

Direct fistulas can cause acute symptoms or manifest after days or months. They are usually $1-5 \mathrm{~mm}$ in size and $1-2 \%$ are bilateral, or even contralateral to the ophthalmic signs ${ }^{(8,29)}$. Indirect $\mathrm{CCF}$, also called dural shunt, is typically a low-flow condition which may be congenital or occur spontaneously, and which causes or results from venous thrombosis. Predisposing factors include hypertension, pregnancy, head trauma and stretching, post-menopause, thromboembolic disease, atherosclerosis, and collagen disease ${ }^{(10,30,31)}$. Indirect spontaneous forms are much more frequent than direct forms ${ }^{(32)}$. Spontaneous resolution in direct CCF occurs in $10-60 \%$ of cases, before or after angiography, possibly due to CS thrombosis, usually within 6-94 months ${ }^{(8,20,33,34)}$.

Different subtypes of CCF cause different clinical signs, with varying speeds of onset and severity, which is usually higher in direct forms. Pathogenesis involves CS dilation and retrograde drainage (cortex and orbit), with increased vascular volume and enlarged orbital muscles, increased capillary transudation, elevated episcleral venous pressure, and impairment of the optic nerve and retina due to stasis. In direct CCF, these events lead to a more acute presentation with more abundant signs and symptoms ${ }^{(9,23,35-37)}$. Indirect forms, however, have a milder or minimal presentation. This is possibly due to the fact that in many cases, drainage of dural shunts often occurs to the basal and petrosal sinus, and only in the presence of thrombosis there is flow back into the orbit ${ }^{(3,12,32,38-40)}$.

Clinical signs range from mild paresis and dysfunctions (nerves III, V, VI - the latter involved in up to $85 \%$ of $\operatorname{cases}^{(8)}$ ) without orbital congestion to pulsatile proptosis (milder in indirect forms). When CCF drainage flows to petrosal sinus, the SOV can have normal dimensions with a quiet eye (with some paresis, a condition called "white-eyed cavernous shunt")(8). Signs and symptoms include: Chemosis (90\% in type A), pain $(25-40 \%)$, diplopia (50-68\%), episcleral venous dilation with arterialisation, glaucoma $\left(50-83 \%\right.$, with pulse asymmetry on tonometry $\left.{ }^{(41)}\right)$, murmur in the orbital region and surroundings (less dramatic or absent in dural forms; in order to assess it, the patient should be instructed to look down with the opposite eye, reducing involuntary movements and blinking), intracranial haemorrhage $(5 \% \text {, type } A)^{(42)}$, and epistaxis $(1-2 \% \text {, type } A)^{(1,3,26,32,40,43-49)}$.
Characteristic symptoms include pulsatile exophthalmos, murmur and venular dilation with chemosis (Dandy's triad) ${ }^{(2)}$. A change in the nature of the murmur may indicate improvement or a change in the drainage pattern ${ }^{(32,50)}$. Children often have orbital murmurs, therefore the isolated presence of this finding after head trauma does not necessarily indicate fistula ${ }^{(38,39)}$.

Increased muscle volume together with paresis produced in the CS cause diplopia and ophthalmoplegia ${ }^{(11,23)}$. Ocular and orbital venous stasis causes circulatory distress of the optic nerve and retina, leading to papilledema, venular engorgement, retina-choroidal folds, retinal capillary disease (ischemia, oedema, haemorrhage $)^{(51)}$. A chronic lack of adequate perfusion in these sites can cause venous occlusion, proliferative retinopathy, vitreous haemorrhage, choroidal detachment, and neovascular glaucoma ${ }^{(52,53)}$. Severe proptosis, eyelid cyanosis, and chemosis (possibly with spontaneous bleeding or after minimal trauma, and sometimes affecting the corneal surface [exposure keratopathy]) are associated with increased blood flow ${ }^{(8,15,18)}$. Visual loss $(90 \%$ in direct forms; rarely mild or bilateral) can be acute (associated with damage to II nerve) or gradual ${ }^{(1,22,28,48,54)}$.

Glaucoma can be caused by episcleral hypertension (20$25 \%$ present with blood in Schlemm's canal), neovascularisation, or anterior displacement of the iris-lens diaphragm ${ }^{(52,53,55,56)}$.

\section{Diagnosis and diferential diagnosis}

Diagnostic suspicion is stronger in cases with a variety of characteristic signs. However, the gold standard for any type of $\mathrm{CCF}$ is cerebral angiography. It identifies the type, location and size of the connection, examines the vascular surroundings (aneurysms, pseudo-varices), and co-existing alterations, especially ischemic effects on the cortex. The main complications of the procedure include cerebral infarction (0.1-0.5\%), adverse effects related to the contrast material, and death $(0.1 \%)^{(8,10,12,25,32,57)}$.

Initial evaluation is done with Doppler ultrasound ${ }^{(50,58)}$, computed tomography ${ }^{(5)}(\mathrm{CT})$, and magnetic resonance imaging $^{(4,26)}(\mathrm{MRI})$. Note that normal results in these tests do not exclude the diagnosis ${ }^{(11,12)}$. Additional techniques such as image subtraction or CT angiography can be used ${ }^{(4)}$. CT can assess proptosis, CS and SOV dilation, enlargement of the extrinsic muscles (without predominance of specific muscles, such as the inferior and middle recti in Graves' ophthalmopathy ${ }^{(59)}$ ), and bone fractures. Richer details are obtained with MRI, which shows the condition of the other brain sinuses, signs of hypertension, oedema, and cortical, cerebellar or brainstem involvement ${ }^{(4,26)}$. This method and its improvements can achieve $83 \%$ sensitivity and $100 \%$ specificity ${ }^{(5)}$. The SOV is increased in $75-100 \%$ of cases and may be the only imaging finding; it is rarely bilateral, and can even be contralateral (in cases with atypical drainage $)^{(2,4,12)}$. Occasionally remissions and exacerbations can occur, which is explained by SOV thrombosis, a differential diagnosis detected by MRI ${ }^{(22)}$.

Ultrasound is useful in differentiating between dural and direct types, but also on follow-up. Increased flow turbulence in the ICA or ECA, inversion and arterialisation of vascular flow are characteristic signs ${ }^{(50,58)}$.

Not every post-traumatic exophthalmos is due to CCF. Fractures of the orbital floor produce pain and exophthalmos (brain herniation) without murmur. Rarer types of fistula, such as a connection between the $\mathrm{CS}$ and the posterior communicating artery or the meningeal artery produce a similar presentation. Chronic conjunctivitis, orbital pseudotumor, Graves' disease, inflammation (Tolosa-Hunt syndrome ${ }^{(60)}$ ), and thrombophlebitis of the CS are among possible differential diagnoses ${ }^{(2,3,26,27,30,43,59,61,62)}$ (Table 2). 
Table 2

\section{Differential diagnosis of CCF}

\begin{tabular}{|c|c|}
\hline Disease & Differential features \\
\hline Orbital cellulitis & $\begin{array}{l}\text { External or lacrimal infection, trauma, involvement of paranasal sinuses, fever, rhinorrhoea, } \\
\text { malaise, leukocytosis }\end{array}$ \\
\hline Graves exophthalmos & $\begin{array}{l}\text { Evidence of systemic disease, slow progression with exacerbation, upper eyelid retraction, lid } \\
\text { lag, T3-T4-TSH. }\end{array}$ \\
\hline Orbital pseudotumour & $\begin{array}{l}\text { Varying onset, muscle-tendon involvement, proptosis, isolated thickening of the lateral rectus, } \\
\text { bilateral in } 25 \% \text {, pain on movement, variable loss of acuity, affects the anterior portion (palpable } \\
\text { lacrimal gland), signs of uveitis, serous retinal detachment. }\end{array}$ \\
\hline Tolosa-Hunt & $\begin{array}{l}\text { Persistent retro-ocular pain (preceding paresis), variable loss of acuity, symptoms lasting days } \\
\text { or weeks, recurring, responding to corticosteroids in } 24-48 \mathrm{~h} \text {, anomalous tissue in the superior } \\
\text { orbital fissure on CT }\end{array}$ \\
\hline Cavernous sinus thrombophlebitis & $\begin{array}{l}\text { Fever }(30-90 \%) \text {, rapid progression (bilateral), foci of infection (sinusitis, face [25\%], ear, teeth, } \\
\text { gums), leukocytosis, affects the patient's clinical condition (confusion, seizures, stupor, coma), } \\
\text { death }<30 \%\end{array}$ \\
\hline
\end{tabular}

\section{Management}

Emergency endovascular treatment of CCF is indicated in the presence of pseudoaneurysm, large CS varix, venous drainage toward the cortex, thrombosis extending beyond the fistula, increased intracranial pressure, altered mental status, proptosis and/or progressive loss visual acuity, brain haemorrhage, and ischemic stroke ${ }^{(6,16,17,25,63,64)}$.

In other situations, the severity of the condition versus the possibility of spontaneous resolution should be taken into account, especially in dural forms ${ }^{(32,40)}$. Neuro-endovascular treatment should be used only when conservative management proves ineffective, or before ocular surgical procedures ${ }^{(27,32,40,63)}$.

The endovascular approach is the current procedure of choice, either through an arterial or venous access. Different natural or synthetic occlusive materials can be used: Absorbable gelatin (gelfoam), silastic, silicone, platinum coils, autologous blood or blood products, polyvinyl alcohol, ethanol, cyanoacrylate, concomitant radiosurgery $(6,17,23,24,28,29,32,57,64-68)$. About $75 \%$ of cases have some permanent loss of visual acuity ${ }^{(44)}$. Different studies found $85-90 \%$ success rates, and complications range from 5 to $8 \%(\text { death in } 1 \%)^{(8,29,35)}$. Relapse is not uncommon ${ }^{(8)}$. Indirect $\mathrm{CCF}$ is treated more conservatively, considering the lower severity, the chance of spontaneous resolution and the risks of interventions ${ }^{(32,40)}$. Symptoms can often worsen after successful occlusion (intentional or accidental) of the fistula, but there seems to be no higher risk of death in this subgroup than in patients without dural fistula ${ }^{(32,69,70)}$.

Manual compression of the ipsilateral carotid artery and jugular vein can help closing up to $30 \%$ of dural $\mathrm{CCFs}^{(71)}$. This manoeuvre should be performed using the contralateral hand (thus any deficit in this arm acts as a warning and a safety mechanism to interrupt compression) for 10 seconds, 5-6 times every hour. Compression should be increased over a few weeks ${ }^{(29)}$. There are some contraindications to compression. Absolute contraindications are: Hypersensitive carotid sinus syndrome, carotid stenosis due to atherosclerosis or carotid ulceration, vertebrobasilar insufficiency, syncope or hypotension, transient ischemic attack, cardiac arrhythmia, and previous haemorrhage around the CCF. Relative contraindications are: Eye pressure above $25 \mathrm{mmHg}$ with severe visual field loss, and severe vision $\operatorname{loss}{ }^{(71,72)}$.
Proptosis, chemosis and keratopathy should be managed according to severity. Lubricants (eye drops, gels), forced nocturnal eyelid occlusion, and topical antibiotics (when appropriate) are often necessary ${ }^{(46)}$.

For glaucoma, drugs that reduce the production of aqueous humour are indicated (beta-blockers, alpha-adrenergic agonists, carbonic anhydrase inhibitors), while drugs promoting drainage are ineffective (pilocarpine and prostaglandin analogues) ${ }^{(55)}$. Fistulising surgery (trabeculectomy with or without mitomycin) may be necessary; care should be taken to leave some posterior sclerotomies for the management of possible choroidal effusion $^{(56)}$. Neovascular forms (glaucoma and retinopathy), when associated, require laser panphotocoagulation and/or drainage valves $^{(36,52)}$. Nonproliferative retinal repercussions are managed conservatively ${ }^{(73)}$.

A study by Ishijima et $\mathrm{al}^{(52)}$, which included the largest number of CCF cases complicated with glaucoma, showed good general prognosis, largely related to primary occlusion. With CCF closure most signs disappear within varying times (eye pressure in 72 hours, on average), but visual damage and some paresis may persist.

\section{REFERÊNCIAS}

1. Albert GW, Dahdaleh NS, Hasan DM. Direct carotid-cavernous fistula presenting with minimal symptoms and rapid angiographic progression. J Clin Neurosci. 2010;17(9):1187-9.

2. Biousse V,Mendicino ME, Simon DJ,Newman NJ.The ophthalmology of intracranial vascular abnormalities. Am J Ophthalmol. 1998;125(4):52744. Comment in Am J Ophthalmol. 1998;126(6):852-3

3. de Keizer R. Carotid-cavernous and orbital arteriovenous fistulas: ocular features, diagnostic and hemodynamic considerations in relation to visual impairment and morbidity. Orbit. 2003;22(2):121-42.

4. Ettl A, Zwrtek K, Daxer A, Salamonowitz E. Anatomy of the orbital apex and cavernous sinus on high-resolution magnetic resonance images. Surv Ophthalmol. 2000;44(4):303-23.

5. Hirai T, Korogi Y, Hamatake S, Ikushima I, Sugahara T, Sigematsu Y, et al. Three-dimensional FISP imaging in the evaluation of carotid cavernous fistula: comparison with contrast-enhanced CT and spinecho MR. AJNR Am J Neuroradiol. 1998;19(2):253-9.

6. Tjoumakaris SI, Jabbour PM, Rosenwasser RH. Neuroendovascular management of carotid cavernous fistulae. Neurosurg Clin N Am. 2009;20(4):447-52. 
7. Machado A. Neuroanatomia funcional. Rio de Janeiro: Atheneu;1979.

8. Ringer AJ, Salud L, Tomsick TA. Carotid cavernous fistulas: anatomy, classification, and treatment. Neurosurg Clin N Am. 2005;16(2):279-95, viii.

9. Helmke K, Krüger O, Laas R. The direct carotid cavernous fistula: a clinical, pathoanatomical, and physical study. Acta Neurochir (Wien). 1994;127(1-2):1-5.

10. Newton TH, Hoyt WF. Dural arteriovenous shunts in the region of the cavernous sinus. Neuroradiology. 1970;1(2):71-81.

11. Tytle TL,Punukollu PK. Carotid cavernous fistula. Semin Cerebrovasc Dis Stroke. 2001;1(1):83-111.

12. Barrow DL, Spector RH, Braun IF, Landman JA, Tindall SC, Tindall GT. Classification and treatment of spontaneous carotid cavernous sinus fistulas. J Neurosurg. 1985;62(2):248-56.

13. Bouthillier A, van Loveren HR, Keller JT. Segments of the internal carotid artery: a new classification. Neurosurgery. 1996;38(3):425-32; discussion 432-3.

14. Harris FS, Rhoton AL. Anatomy of the cavernous sinus. A microsurgical study. J Neurosurg. 1976;45(2):169-80.

15. Phatouros CC, Meyers PM, Dowd CF, Halbach VV, Malek AM, Higashida RT. Carotid artery cavernous fistulas. Neurosurg Clin N Am. 2000;11(1):67-84, viii.

16. Debrun G, Lacour P, Vinuela F, Fox A, Drake CG, Caron JP.Treatment of 54 traumatic carotid-cavernous fistulas. J Neurosurg. 1981;55(5):678-92.

17. Larson JJ, Tew JM Jr, Tomsick TA, van Loveren HR. Treatment of aneurysms of the internal carotid artery by intravenous balloon occlusion: long-term follow-up of 58 patients. Neurosurgery. 1995;36(1):26-30; discussion 30.

18. Peeters FL, Kröger R. Dural and direct cavernous fistulas. AJR Am J Roentgenol. 1979;132(4):599-606.

19. Farley MK, Clark RD, Fallor MK, Geggel HS, Heckenlively JR. Spontaneous carotid-cavernous fistula and the Ehlers-Danlos syndromes. Ophthalmology. 1983;90(11):1337-42.

20. Kim CK, Shim JY, Chang JY, Lee SH. Spontaneous carotid cavernous fistula in a case with protein $\mathrm{S}$ deficiency that newly developed ophthalmoplegia after embolization. J Clin Neurol. 2011;7(3):164-7.

21. Levin LA. Neuro-ophthalmologic diagnosis and therapy of central nervous system trauma. Ophthamol Clin North Am. 2004;17(3):45564, vii. Review.

22. Naesens R, Mestdagh C, Breemersch M, Defreyne L. Direct carotidcavernous fistula: a case report and review of the literature. Bull Soc Belge Ophtalmol. 2006;(299):43-54. Review.

23. Taki W,Nakahara I,NishiS, Yamashita K,Sadatou A,Matsumoto K,Tanaka M, Kikuchi H. Pathogenetic and therapeutic considerations of carotidcavernous sinus fistulas. Acta Neurochir (Wien). 1994;127(1-2):6-14.

24. Parkinson D. Transcavernous repair of carotid cavernous fistula. Case report. J Neurosurg. 1967;26(4):420-4.

25. Gobin YP, Duckwiller GR, Viñuela F. Direct arteriovenous fistulas (carotid-cavernous and vertebral-venous). Diagnosis and intervention. Neuroimaging Clin N Am. 1998;8(2):425-43.

26. Lee JH, Lee HK, Park JK, Choi CG, Suh DC. Cavernous sinus syndrome: clinical features and differential diagnosis with MR imaging. AJR Am J Roentgenol. 2003;181(2):583-90.

27. Chaudhry IA, Elkhamry SM, Al-Rashed W, Bosley TM. Carotid cavernous fistula: ophthalmological implications. Middle East Afr J Ophthalmol. 2009;16(2):57-63.

28. Schneider-Lise B, Vignal-Clermont C, Gastaud P. [Carotid-cavernous fistulas: clinical features, management and differential diagnosis]. Rev Neurol (Paris). 2010;166(12):1010-6. Review. French.

29. Crespo Rodríguez AM, Angulo Hervías E, Franco Uliaque C, Guillén Subirán ME, Barrena Caballo MR, Guelbenzu Morte S. Tratamiento de fístulas carótido-cavernosas. Radiologia. 2006;48(6):375-83.

30. Taniguchi RM, Goree JA, Odom GL. Spontaneous carotid-cavernous shunts presenting diagnostic problems. J Neurosurg. 1971;35(4):384-91.

31. Toya S, Shiobara R, Izumi J, Shinomiya Y, Shiga H, Kimura C. Spontaneous carotid-cavernous fistula during pregnancy or in the post-partum stage. Report of two cases. J Neurosurg. 1981;54(2):252-6.

32. Miller NR. Diagnosis and management of dural carotid-cavernous sinus fistulas. Neurosurg Focus. 2007;23(5):E13.

33. Sasaki H, Nukui H, Kaneko M, Mitsuka S, Hosaka T, Kakizawa T, et al. Long-term observations in cases with spontaneous carotid-cavernous fistula. Acta Neurochir (Wien), 1988;90(3-4):117-20.

34. Yu JS, Lei T, Chen JC,He Y, Chen J, Li L. Diagnosis and endovascular treatment of spontaneous direct carotid-cavernous fistula. Chin Med J (Engl). 2008;121(16):1558-62.

35. Barry RC, Wilkinson M,Ahmed RM, Lim CS, Parker GD, McCluskey PJ, Halmagyi GM. Interventional treatment of carotid cavernous fistula. J Clin Neurosci. 2011;18(8):1072-9.

36. Grove AS Jr. The dural shunt syndrome. Pathophysiology and clinical course. Ophthalmology. 1984;91(1):31-44.

37. Das JK, Medhi J, Bhattacharya P, Borah N, Bhattacharjee K, Kuri GC et al. Clinical spectrum of spontaneous carotid-cavernous fistula. Indian J Ophthalmol. 2007;55(4):310-2.

38. Kurul S, Cakmakçi H, Kovanlikaya A, Dirik E. The benign course of carotid-cavernous fistula in a child. Eur J Radiol. 2001;39(2):77-9.

39. Lau FH, Yuen HK, Rao SK, Lam DS. Spontaneous carotid cavernous fistula in a pediatric patient: case report and review of literature. $\mathrm{J}$ AAPOS. 2005;9(3):292-4.

40. Miller NR. Dural carotid-cavernous fistulas: epidemiology, clinical presentation, and management. Neurosurg Clin N Am. 2012;23(1):179-92.

41. Golnik KC, Miller NR. Diagnosis of cavernous sinus arteriovenous fistula by measurement of ocular pulse amplitude. Ophthalmology. 1992;99(7):1146-52. Comment in Ophthalmology. 1993;100(1):2-3.

42. Gierthmuehlen M, Schumacher M, Zentner J, Hader C. Brainstem compression caused by bilateral traumatic carotid cavernous fistula: case report. Neurosurgery. 2010;67(4):E1160-3; discussion E1163-4.

43. Bhatti MT, Peters KR. A red eye and then a really red eye. Sury Ophthalmol. 2003;48(2):224-9.

44. Eggenberger E, Lee AG, Forget TR Jr, Rosenwasser R.A bruital headache and double vision. Surv Ophthalmol. 2000;45(2):147-53.

45. Ekinci B, Koktekir E, Kal A, Karalezli A. Proptosis, congestion, and secondary glaucoma due to carotid-cavernous fistula after embolization. J Craniofac Surg. 2011;22(5):1963-5.

46. Kellog JX, Kuether TA, Horgan MA, Nesbit GM, Barnwell SL. Current concepts on carotid artery-cavernous sinus fistulas. Neurosurg Focus. 1998;5(4):e12.

47. Lamirel C, Newman NJ, Biousse V. Vascular neuro-ophthalmology. Neurol Clin. 2010;28(3):701-27.

48. Plant GT. Visual disturbances. Medicine. 2008;36(10):520-5.

49. Sedwick LA, Kaufman DI, Fratkin J. Really painfull double vision. Surv Ophthalmol. 2000;45(2):155-9.

50. Kotval PS, Weitzner I Jr, Tenner MS. Diagnosis of carotid-cavernous fistula by periorbital color Doppler imaging and pulsed Doppler volume flow analysis. J Ultrasound Med. 1990;9(2):101-6.

51. Gonshor LG, Kline LB. Choroidal folds and dural cavernous sinus fistula. Arch Ophthalmol. 1991;109(8):1065-6.

52. Ishijima K, Kashiwagi K, Nakano K, Shibuya T,Tsumura T, Tsukahara S Ocular manifestations and prognosis of secondary glaucoma in patients with carotid-cavernous fistula. Jpn J Ophthalmol. 2003;47(6):603-8.

53. Talks SJ, Salmon JF, Elston JS, Bron AJ. Cavernous-dural fistula with secondary angle-closure glaucoma. Am J Ophthalmol. 1997;124(6):851-3.

54. Yu JK, Hwang G, Sheen SH, Cho YJ. Bilateral visual loss as a sole manifestation complicating carotid cavernous fistula. J Korean Neurosurg Soc. 2011;49(4):229-30.

55. Nassr MA, Morris CL, Netland PA, Karcioglu ZA. Intraocular pressure change in orbital disease. Surv Ophthalmol. 2009;54(5):519-44.

56. Parikh RS, Desai S, Kothari K. Dilated episcleral veins with secondary open angle glaucoma. Indian J Ophthalmol. 2011;59(2):153-5.

57. Théaudin M, Saint-Maurice JP, Chapot R, Vahedi K, Mazighi M, Vignal C, et al. Diagnosis and treatment of dural carotid-cavernous fistulas: a consecutive series of 27 patients. J Neurol Neurosurg Psychiatry. 
2007:78(2):174-9.

58. Chen YW, Jeng JS, Liu HM, Hwang BS, Lin WH, Yip PK. Carotid and transcranial color-coded duplex sonography in different types of carotid-cavernous fistula. Stroke. 2000;31(3):701-6.

59. Bartalena L, Tanda ML. Clinical practice. Graves' ophthalmopathy. N Eng J Med. 2009;360(10):994-1001. Review.

60. Kline LB, Hoyt WF. The Tolosa-Hunt syndrome. J Neurol Neurosurg Psychiatry. 2001;71(5):577-82. Review.

61. Dini LI, Sonda I, Saraiva GA, Corso RJ,Almeida FO, Gallo P.Trombose séptica do seio cavernoso: relato de seis casos. Arq Neuropsiquiatr. 1999;57(3-A):643-8

62. Turkoglu R, Baiak N. Atypical presentation of orbital pseudotumor with visual loss as an initial manifestation. J Clin Neurol. 2011;7(1):502.

63. Debrun GM, Viñuela F, Fox AJ, Davis KR, Ahn HS. Indications for treatment and classification of 132 carotid-cavernous fistulas. Neurosurgery. 1988;22(2):285-9.

64. Gemmete JJ, Ansari SA, Gandhi D. Endovascular treatment of carotid cavernous fistulas. Neuroimaging Clin N Am. 2009;19(2):24155, Table of Contents.

65. Dabes G, Batjer HH, Hurley MC, Nimmagadda A, Russell EJ. Endovascular treatment of a bilateral dural carotid-cavernous fistula using an unusual unilateral approach through the basilar plexus. World Neurosurg. 2011 Nov 19. [Epub ahead of print].

66. Meyers PM,Halbach VV,Dowd CF,LempertTE, Malek AM, Phatouros $\mathrm{CC}$, et al. Dural carotid cavernous fistula: definitive endovascular management and long-term follow-up. Am J Ophthalmol. 2002;134(1):85-92.

67. Yang HC, Kano H, Kondziolka D, Niranjan A, Flickinger JC, Horowitz MB, Lunsford LD. Stereostactic radiosurgery with or without embolization for intracranial dural arteriovenous fistulas. Neurosurgery 2010;67(5):1276-83; discussion 1284-5. Comment in Neurosurgery. 2011;69(3):E789-90; author reply E790.
68. Zaidat OO, Lazzaro MA, Niu T, Hong SH, Fitzsimmons BF, Lynch JR, Sinson GP. Multimodal endovascular therapy of traumatic and spontaneous carotid cavernous fistula using coils, n-BCA, Onyx and stent graft. J Neurointerv Surg. 2011;3(3):255-62.

69. Gupta N, Kikkawa DO, Levi L, Weinreb RN. Severe vision loss and neovascular glaucoma complicating superior ophthalmic vein approach to carotid-cavernous sinus fistula. Am J Ophthalmol. 1997;124(6):853-5

70. Sergott RC, Grossman RI, Savino PJ, Bosley TM, Schatz NJ. The syndrome of paradoxical worsening of dural-cavernous sinus arteriovenous malformations. Ophthalmology. 1987;94(3):205-12.

71. Higashida RT, Hieshima GB, Halbach VV, Bentson JR, Goto K. Closure of carotid cavernous sinus fistulae by external compression of the carotid artery and jugular vein. Acta Radiol Suppl. 1986;369:580-3.

72. Kai Y,Hamada J, Morioka M, Yano S, Kuratsu J. Treatment of cavernous sinus dural arteriovenous fistulae by external manual carotid compression. Neurosurgery. 2007;60(2):253-7; discussion 257-8.

73. Harris MJ, Fine SL, Miller NR. Photocoagulation treatment of proliferative retinopathy secondary to a carotid-cavernous sinus fistula. Am J Ophthalmol. 1980;90(4):515-8.

\section{Corresponding author: \\ Manuel A P Vilela}

Rua Félix da Cunha, nº 496

Bairro Floresta

CEP 90570-000 - Porto Alegre - RS

mapvilela@gmail.com 